\title{
Dust exposure in coeliac disease: a case-referent study
}

\author{
B Axmacher, O Axelson, T Frödin, R Gotthard, J Hed, L Molin, H Noorlind Brage, M Ström
}

\begin{abstract}
Case series of coeliac disease show that chronic allergic alveolitis (farmers' lung) and fever reactions due to exposure to organic dust (organic dust toxic syndrome) commonly occur among subjects with coeliac disease and dermatitis herpetiformis, these being related disorders. In this case-referent study 105 cases of coeliac disease and dermatitis herpetiformis were compared with 237 referents from the general population by means of a mail inquiry regarding exposure to various environmental factors. Increased odds ratios were obtained with exposure to various farm animals and more clearly for cotton dust, although numbers were few. Animal husbandry in Sweden invariably means heavy exposure to organic dust. The fact that comparatively few persons reported dust exposure may be of doubtful validity in view of the high frequency of exposure to farm animals reported by the cases.
\end{abstract}

Coeliac disease or gluten intolerance is known to occur concomitant with other disorders, most commonly together with dermatitis herpetiformis. Coeliac disease has attracted considerable attention especially in the past $10-15$ years when several studies from different countries have indicated that it is more common than usually appreciated and not restricted to children. ${ }^{1-3}$ The prevalence has been reported to be in the range of 0.1 to $0.2 \%$ among children. ${ }^{2}$ Hallert et al, ${ }^{4}$ in a survey from the Swedish

Swedish Farmers' Safety and Preventive Health Association, Högmarksvägen 2, S 61400 Söderköping, Sweden

B Axmacher

Department of Occupational Medicine, University Hospital, Linköping, Sweden

$O$ Axelson, $H$ Noorlind Brage

Department of Dermatology, Örebro Medical Center Hospital, Orebro, Sweden

T Frödin, L Molin

Department of Internal Medicine, University

Hospital, Linköping, Sweden

R Gotthard, M Ström

Clinical Immunology Laboratory, University Hospital, Linköping, Sweden

J Hed county of Östergötland in 1981, stated that the local prevalence among adults reached $0 \cdot 13 \%$ if dermatitis herpetiformis was included in the disease entity. Further, they suggested that some cases in the area go unrecognised.

Apart from the relation to allergic alveolitis ${ }^{5-7}$ and a suggestion that an adenovirus infection could be of aetiological importance, ${ }^{8}$ coeliac disease is not yet considered to be related to environmental exposures. Using antibodies raised against gliadin, however, Axmacher et $a l^{9}$ found a prevalence of $0.9 \%$ in a small population of farmers in the Swedish county of Östergötland, all of whom were affiliated to the Swedish Farmers' Safety and Preventive Health Association. At least two of 22 cases also had allergic alveolitis and 13 of the remaining 20 had experienced one or several attacks of organic dust toxic syndrome (or acute allergic alveolitis)-that is, fever and chills after exposure to organic dust, mostly from mouldy grain, hay, and straw. Thirteen cases were previously unrecognised, which confirms the assumption that many cases are overlooked.

The observations referred to indicate a connection between coeliac disease and exposure to organic dust. This case-referent study was therefore undertaken to investigate the connection, considering exposure to dust in farm work and other environments.

\section{Materials and methods}

All subjects known to have coeliac disease at the Department of Internal Medicine of the University Hospital in Linköping and all subjects with dermatitis herpetiformis at the Department of Dermatology in the same hospital were enrolled as cases, provided that they were of Swedish ethnicity, born 1916-65 inclusive, and living in the mail districts that constitute the primary catchment area of the University Hospital in Linköping. One hundred and ten cases were obtained; 35 of them had dermatitis herpetiformis.

The diagnostic criteria for coeliac disease were positive jejunal biopsy followed by a negative biopsy after about one year on a gluten free diet. The criterion for dermatitis herpetiformis was a typical clinical picture, and 29 subjects tested showed positive immunofluorescence for IgA, or a positive histopathological diagnosis, or both. 
Table 1 All exposures with crude rate ratio $(C R R)>1 \cdot 2$ and at least four exposed cases (occupational and nonoccupational exposures aggregated)

\begin{tabular}{llll}
\hline & & \multicolumn{2}{l}{$\begin{array}{l}\text { No of exposed } \\
\text { subjects }\end{array}$} \\
\cline { 3 - 4 } $\begin{array}{l}\text { Type of } \\
\text { exposure }\end{array}$ & $\begin{array}{l}\text { CRR } \\
(90 \% C I)\end{array}$ & Cases & Referents \\
\hline Poultry & $1 \cdot 8(1 \cdot 1-2 \cdot 9)$ & 26 & 37 \\
Cows & $1 \cdot 4(0 \cdot 92-2 \cdot 2)$ & 31 & 54 \\
Horses & $1 \cdot 5(0 \cdot 96-2 \cdot 4)$ & 28 & 46 \\
Swine & $1 \cdot 3(0 \cdot 83-2 \cdot 2)$ & 23 & 41 \\
Other animals & $1 \cdot 4(0 \cdot 68-2 \cdot 9)$ & 9 & 15 \\
Flour & $2 \cdot 0(1 \cdot 0-4 \cdot 0)$ & 11 & 13 \\
Other solvents & $2 \cdot 1(1 \cdot 0-4 \cdot 1)$ & 12 & 14 \\
Dust: & $1 \cdot 2(0 \cdot 84-1 \cdot 9)$ & 48 & 96 \\
$\quad$ Total $\dagger$ & $4 \cdot 7(1 \cdot 2-22)$ & 6 & 3 \\
\hline Cotton & & & \\
\hline
\end{tabular}

* Of a total of 105 cases and 237 referents.

tAll answers to questions about organic dust aggregated.

Three hundred referents were randomly drawn from the general population in the same age range and with the same geographical restrictions as the cases. Another referent was drawn if it was apparent from the name of the first referent that he or she was an immigrant, or if the referent had moved out of the catchment area. This applied to five referents.

After an introductory letter, identical for cases and referents, all participating subjects were sent a questionnaire. The purpose of the study was stated in general terms indicating that relations between disease and occupational or environmental factors were being investigated; the specific nature of the study was not revealed.

Apart from questions concerning exposure to dust and environmental factors in farm work, questions were presented on other types of occupational exposures for the purpose of diversion. Most exposure could be attributed to work, leisure time, or both. Reminder letters to non-responders were sent twice. The different topics of the questions are listed in brief in the appendix.

One hundred and five out of 110 cases and 237 out of 300 referents responded. In the analysis the material was stratified by sex and by age in three categories-namely, 20-44, 45-59, and 60-70 years.

\section{Results}

The frequency of exposure to many agents turned out to be very low, making an analysis meaningless. Table 1 lists associations with a crude rate ratio of more than 1.2 after excluding all exposures with less than four exposed cases.

Because exposure to animals was of particular interest and the numbers of exposed subjects were reasonable, a stratified analysis was undertaken for this parameter and table 2 lists the results.

\section{Discussion}

The hypothesis of this study was that exposure to various kinds of organic dust in farming might be causally related to coeliac disease. Exposure to unspecified dust was associated with an increased odds ratio although with the $90 \%$ confidence interval encompassing unity. The exposure frequencies to specific dusts were too low to permit any conclusions. In general, however, it can be assumed that exposure to fine particular dust may have been under-reported but exposure to coarse, non-respirable dust on the other hand may have been over-reported.

Exposure to flour appeared more common among the cases than among the referents, but bias must be suspected as people with coeliac disease are familiar with the connection between flour and the disorder. Exposure to what was labelled "other solvents" was also raised among the cases, but the question might have been misunderstood as a long list of specified solvents with many well known solvents included did not bring out any positive associations.

Questions on exposure to animals can be expected to result in a valid answer, leaving little room for misconceptions. Even if none of the rate ratios found clearly exceeded unity, it is interesting to note that exposure to all animals connected with animal husbandry was associated with an increased risk, whereas exposure to pets (dogs and cats) was not. Farm animals in Sweden are always kept in confinement at least during the winter, and this invariably means that tending the animals is associated with heavy exposure to dust of organic origin. Taking farming as such as an exposure, there was no increased risk, however, indicating that the connection is limited to specific exposures and disease.

A slightly raised occurrence of organic dust toxic syndrome was found among the cases in comparison with the referents. The condition is common and roughly one farmer in ten has experienced one or more attacks. ${ }^{10}$ The knowledge of this syndrome,

Table 2 Mantel-Haenszel analyses on exposures to animals among cases and referents

\begin{tabular}{llll}
\hline & & \multicolumn{2}{l}{$\begin{array}{l}\text { No of exposed } \\
\text { subjects }\end{array}$} \\
\cline { 2 - 4 } Exposure & $\begin{array}{l}\text { MHRR } \\
(90 \%(C I)\end{array}$ & Cases & Referents \\
\hline Poultry & $1 \cdot 4(0 \cdot 85-2 \cdot 4)$ & 26 & 37 \\
Cows & $1 \cdot 4(0 \cdot 87-2 \cdot 2)$ & 31 & 54 \\
Horses & $1 \cdot 3(0 \cdot 82-2 \cdot 2)$ & 28 & 46 \\
Swine & $1 \cdot 2(0 \cdot 74-2 \cdot 1)$ & 23 & 40 \\
All farm animals & $1 \cdot 4(0 \cdot 95-2 \cdot 2)$ & 40 & 68 \\
Other animals & $1 \cdot 1(0 \cdot 52-2 \cdot 3)$ & 9 & 25 \\
Dogs & $0 \cdot 70(0 \cdot 47-1 \cdot 1)$ & 44 & 116 \\
Cats & $0 \cdot 71(0 \cdot 47-1 \cdot 1)$ & 39 & 106 \\
Cage birds & $0 \cdot 83(0 \cdot 48-1 \cdot 5)$ & 20 & 46 \\
\hline
\end{tabular}

^Of a total of 105 cases and 237 referents.

MHRR = Mantel-Haenszel rate ratio.

Stratification on age and sex not shown in table.

Occupational and non-occupational exposures aggregated. 
however, is poor among laymen and the symptoms are often misinterpreted as a slight influenza. Thus the validity of the answers may be in question, especially among non-farmers.

One of the causes of organic dust toxic syndrome is suggested to be exposure to bacterial endotoxins, often found in high concentrations in various organic dusts. ${ }^{11}$ As discussed by Rylander ${ }^{12}$ this is particularly the case for cotton dust causing byssinosis. Interestingly, exposure to cotton dust as indicated in the questionnaire, showed the highest rate ratio. Even with the small numbers the question is likely to produce an unbiased response because of the rather specific character of this exposure.

Apart from the difficulty of getting reliable answers on questions about exposure to dust, a main concern about the results could be the possibility that the case series is incomplete and not representative of all the cases in the area, as these disorders may be unrecognised, especially in certain subsets of the population. The overall interpretation of the data in this study, however, indicates that coeliac disease may have some relation with exposure to organic dust. The case series reported by Axmacher et al ${ }^{9}$ indicated a strong association with exposure to dust in farming and, believing this finding to be relevant, it is puzzling that no stronger relation was found in our current study. On the other hand, the possibility exists that the high frequency of exposure to organic dust in farming and the influence of random variation might have merely created the impression of a strong association in the case series reported by Axmacher $e t$ $a l .{ }^{9}$ The possibility also exists that the weak association seen in our study may be attributable to coeliac disease being underdiagnosed in rural areas.

Our study was supported by the Swedish Work Environment Fund.

Requests for reprints to: O Axelson, Department of Occupational Medicine, University Hospital, S-581 85 Linköping, Sweden.

\section{Appendix}

TOPICS OF QUESTIONS

Living

Countryside, village, city.

\section{Occupation}

Farm work, welding, forestry, concrete work, foun- dry work, other heavy work, tractor driving, excavator driving, driver of lorry or bus.

\section{Exposure to solvents}

White spirit, thinner, trichlorethylene, gasoline, styrene, benzene, toluene, carbon tetrachloride, ocetone, cyclohexanone, other solvents.

\section{Exposure to dust}

Hay or straw, grain, chopped wood, sawdust, mould dust from those items, mould dust of other origin, animal confinements, fodder, flour, cotton, dust of other origin.

\section{Threshing}

Grain, red clover, alsike clover, attacks of fever/chill.

Exposure to flour, exhausts

Illness

Pruritus, eczema, asthma, hay fever.

Questions on eating meat or fish, smoking, exercise, hobbies

1 Hallert C. Clinical aspects of adult celiac disease-an overview. Survey of Digestive Diseases 1984;2:92-103.

2 Lebenthal E, Branske D. Childhood celiac disease, a reappraisal. J Pediatr 1981;98:911-6.

3 Swinson CM, Levi AJ. Is coeliac disease underdiagnosed? BMJ 1980;281:1258-60.

4 Hallert C, Gotthard R, Norrby K, Walan A. On the prevalence of adult coeliac disease in Sweden. Scand J Gastroenterol 1981; 16:257-61.

5 Berril WT, Eade OE, Fitzpatrick PF, Hyde I, Macleod WM, Wright $\mathbf{R}$. Bird-fanciers' lung and jejunal villous atrophy. Lancet 1975; ii: $1006-8$.

6 Robinson TJ, Nelson SD, Haire M, Middleton D, McMillan SA, Evans JP. Jejunal villous changes associated with farmer's lung. Postgrad Med J 1981;57:697-701.

7 Robinson TJ. Coeliac disease with farmer's lung. BMJ 1976;ii:1006-10.

8 Kagnoff MF, Austin RK, Hubert JJ, Bernardin JE, Kasarda DD. Possible role for a human adenovirus in the pathogenesis of celiac disease. $J$ Exp Med 1984;160:1544-57.

9 Axmacher B, Hed J, Ottoson E, Ström M. Celiac disease and organic dust toxic syndrome. Am J Ind Med 1990;17:94-5.

10 Malmberg P, Rask-Andersen A, Höglund S, Kolmodin-Hedman B, Guernsey JR. Organic dust toxic syndrome among farmers. Int Arch Allergy Appl Immunol 1988;87:47-53.

11 Rylander R, Peterson Y, Donham KJ, eds. Health effects of organic dusts in the farm environment. Am J Ind Med 1986;10:193-340.

12 Rylander R. Bacterial toxins and the etiology of byssinosis. Chest 1981;79:Suppl 37S-8S.

Accepted 18 February 1991 